\title{
Assessment of Authorial Voice Strength in L2 Argumentative Written Task Performances: Contributions of Voice Components to Text Quality
}

\author{
Reza Zabihi, Mehdi Mehrani-Rad ${ }^{\circ}$ and Ali Khodi* \\ - University of Neyshabur | Iran \\ * University of Tehran | Iran
}

\begin{abstract}
The purpose of this study was twofold: (a) to examine the level of authorial voice strength among Iranian second language (L2) writers; and (b) to investigate the relationship between L2 learners' authorial voice strength and the quality of their argumentative written task performances. Argumentative writing samples were elicited from 129 upper-intermediate L2 learners in writing courses. To quantify learners' voice strength, these samples were scored by two raters using an analytic voice rubric. Raters also provided a holistic rating of the overall authorial voice strength in written argumentations. The quality of argumentations was measured using the TOEFL scoring rubric. While descriptive results indicated that learners demonstrated a low level of voice strength in their argumentations, results from Multiple Regression Analysis (MRA) suggested positive associations between voice strength along with two of its dimensions and the quality of writings. Moreover, results from Multiple Correspondence Analysis (MCA) pointed to the association of low and mid-level of writing quality and low voice strength, and the prevalence of high and mid voice strength in learners with high proficiency in writing. Finally, while an Item Response Theory (IRT) analysis revealed that the 'presence' dimension of authorial voice was the most difficult one for L2 learners, a Differential Item Functioning (DIF) analysis showed that the difficulty of the three voice dimensions did not differ significantly across genders. The findings were discussed regarding English L2 writing within the Iranian context.
\end{abstract}

Keywords: authorial voice, assessment, analytic rubric, L2 writing quality, argumentative writing

\section{$\measuredangle$ WRITING RESEARCH}

Zabihi, R., Mehrani-Rad, M., \& Khodi, A. (2019). Assessment of authorial voice strength in 12 argumentative written task performances: Contributions of voice components to text quality, Journal of Writing Research, 11(2), 331-352. doi: 10.17239/jowr-2019.11.02.04

Contact: Reza Zabihi, English Department, University of Neyshabur, Adib Blvd, Neyshalbur| Iran zabihi@neyshabur.ac.ir

Copyright: Earli | This article is published under Creative Commons Attribution-NoncommercialNo Derivative Works 3.0 Unported license. 


\section{Introduction}

Since its inception in the late 1960s, the notion of 'authorial voice' has undergone various definitions in the literature. Broadly speaking, while some scholars have tended to view authorial voice as self-representation and identity performance in writing (e.g., Bowden, 1999; Elbow, 1981; Stewart, 1972), others have questioned the purely individualistic view of voice, and have argued that voice is socially and culturally constructed where the identity of the writer is co-constructed by the writer and the readers (e.g., Farmer, 1995; Hyland, 2008, 2010; Prior, 2001; Ramanathan \& Atkinson, 1999). Moreover, delving deeper into the literature on authorial voice, one can find other conceptions of the term such as authentic voice (Stewart, 1972), situational voice (Ede, 1989), intertextual voice (Yancey, 1994), and the phenomenological view of voice (Matsuda \& Matsuda, 2010; Yeh, 1998). Given such multifaceted range of definitions, it seems that the answer to the question of what generally constitutes authorial voice has remained elusive.

Regardless of its elusive nature, authorial voice has been considered an important trait in evaluating the overall quality of students' writing (e.g., Llosa, Beck, \& Zhao, 2011; Matsuda \& Jeffery, 2012; Zhao \& Llosa, 2008). For instance, the Wyoming State Board of Education (2003) has characterized voice as "one of the ingredients or traits of good writing that pertains to the personality of the author, the style, mood, or tone of the writing, and matches the purpose and audience of the piece of writing" (p. 76). Furthermore, in the American education system, the majority of the writing rubrics in first language (L1) include authorial voice as an evaluation trait (Jeffery, 2009), a critical element in composition textbooks (Ramanathan \& Kaplan, 1996), and a target objective in teaching writing (Llosa, Beck, \& Zhao, 2011).

However, despite the well-deserved attention given to voice in the area of L1 writing, over the past two decades there has been much debate among researchers about the importance of voice in English L2 writing (L2 writing hereafter). Some researchers (e.g., Cappello, 2006; Elbow, 2007) have cast doubt on the significance of voice-related phenomena in L2 writing research and instruction. There have been arguments in the literature, on both theoretical (Stapleton, 2002) and empirical (HelmsPark \& Stapleton, 2003) grounds, that voice has been given unwarranted attention in L2 writing instruction. The reason for the conscious neglect of voice in L2 writing is twofold. First, it has been argued that learners are more in need of developing basic skills such as sentence level proficiency, grammar, content development, and genre than voice-related skills in L2 composition (Helms-Park \& Stapleton, 2003; Stapleton, 2002). Second, some who tended to ascribe voice to the mainstream ideology of individualism argued that individual voice may be incomprehensible to L2 learners from a collectively oriented cultural background, because there is a discrepancy between some features of individual voice and L2 learners' native culture (e.g., Atkinson, 2001; Elbow, 1999; Hirvela \& Belcher, 2001; Shen, 1989). For these reasons, 
voice has been regarded as a peripheral learning objective in the majority of L2 writing rubrics (Matsuda \& Jeffery, 2012).

Due to the elusiveness of voice and, hence, the difficulty of its operationalization, there is scant empirical research that directly investigates the role of authorial voice in L2 writing quality. What is more, even the handful of existing empirical studies have provided contradictory results. For example, as proponents of the individualistic ideology, Helms-Park and Stapleton (2003) developed a rating scale for measuring intensity of individual voice in L2 texts in terms of assertiveness, self-identification, reiteration of the central idea, and writer presence and autonomy of thought. However, their results did not show any significant relationship between writers' voice intensity and the quality of their writings. On the contrary, having used the same rating scale, Zhao and Llosa (2008) found a strong correlation between high intensity voices and texts with high quality. Following Matsuda and Tardy (2007), who questioned the purely individualistic nature of Helms-Park and Stapleton's rating scale, Zhao (2013) developed an analytic rubric based on Hyland's (2008) interactional voice model that includes both individualistic and interdependent aspects of voice. The interdependent aspect of Zhao's analytic rubric included a reader-engagement dimension in terms of questions, reader pronouns, personal asides, references to shared knowledge, and directives. Having adopted her own analytic rubric to measure authorial voice strength in L2 argumentative writing, Zhao (2017) found that voice was a significant predictor of argumentative essay scores.

Taken together, the inconsistent findings and arguments from the handful of studies show that evidence on the role of authorial voice in the improvement of L2 writing is far from conclusive, which warrants further investigation of the association between authorial voice and quality of L2 learners' writings across different contexts. Having adopted Hyland's (2008) interactional model of voice in the present study, we focus on the Iranian context which has a culture with collectivist orientations (Hofstede, 2001; Saboori, Pishghadam, Fatemi, \& Ghonsooli, 2015).

\section{Review of the Literature}

In what follows, we provide a review of the literature on various definitions and conceptualizations of authorial voice. These are complemented by a review of empirical research carried out on the role of authorial voice in different L2 writing contexts. Here, we explain two reasons why the importance of voice in L2 writing has come under close scrutiny by some researchers. Finally, we state the purposes of the present study.

\subsection{The concept of authorial voice}

Since its introduction in the late 1960s, authorial voice has been conceptualized in different ways, based on various theoretical models in the literature. Voice has traditionally been seen as a purely individual trait (especially in the area of L1 writing) 
and has thus been regarded as the reflection of the writer's identity and expressiveness in writing (Bowden, 1999; Elbow, 1981, 1999; Stewart, 1972). Elbow (1981), for example, described authorial voice as a writer's rhetorical power to develop a writing that "captures the sounds of the individual on the page" (p. 287). In view of this, selfidentification expressions such as 'in my point of view...' or 'I believe that...' as well as intensifiers like 'definitely', 'certainly', or 'must' are among the indicators of authorial voice in a given piece of writing. In a similar vein, Stewart (1992) described what he tends to call 'authentic voice' in writing as "the expression of the essential individuality of a particular writer" (p. 283). From this perspective, voice has mostly been associated with writers' styles of manifesting their unique voices and identities through selecting and combining the linguistic resources available to them (Johnstone, 2000) as well as the use of particular linguistic (e.g., lexical, syntactic, punctuation) features in their writing (Sperling, Appleman, Gilyard, \& Freedman, 2011).

On the other hand, in line with some other researchers (e.g., Hyland, 2008, 2010; Ramanathan \& Atkinson, 1999) in defying the purely individualistic view of authorial voice, Matsuda (2001) has defined voice as "the amalgamative effect of the use of discursive and non-discursive features that language users choose, deliberately or otherwise, from socially available, yet ever changing repertories" (p. 40). Broadly speaking, the idea that the way writers manifest their identities is determined by their society and their respective cultures is reminiscent of Bakhtin's $(1981,1986)$ social theory of language use where all instances of language use are in response to previous utterances/texts and with anticipation of future utterances/texts. Extending the Bakhtinian perspective to the notion of voice in writing raises the idea that writers always deal with responding to other voices. In accordance with the sociocultural view of authorial voice, Hillocks (1995) states that "writing is a recursive process that requires the reconstruction of text already written, so that what we add connects appropriately with what has preceded" (p. xvii). Therefore, projecting one's voice in writing can be regarded as a social act, which is performed as a response to previous voices and ideas. In view of these and given Hyland's (2002) argument that writers manifest their identities in writing by using culturally available resources, it is reasonable to conclude that authorial voice is both social and cultural in nature.

\subsection{The role of authorial voice in $\mathrm{L} 2$ writing}

As mentioned earlier, over the past decades some scholars and researchers have maintained a degree of skepticism about the importance of voice in L2 writing research and instruction. The reason for such a conscious negligence of voice in L2 writing can be twofold: (a) L2 learners' need for more basic writing skills than voice in L2 composition, and (b) the discrepancy between some features of individual voice and L2 learners' native culture.

As regards the first reason for underemphasizing authorial voice in L2 context, it has been argued that writing per se is a demanding task that involves several cognitive mechanisms and interdependent skills (Hayes \& Gradwohl Nash, 1996; Scardamalia, 
1981). In fact, the image of a writer as "a busy switchboard operator trying to juggle a number of demands on her attention and constraints on what she can do" clearly delineates the complexity of the writing task (Flower \& Hayes, 1980, p. 33). Therefore, it goes without saying that writers tend to face far greater challenges when writing in a second or foreign language than when they write in their mother tongue. In view of such complexity involved with the task of L2 writing, Stapleton (2002) has argued that L2 learners are more in need of developing basic skills such as sentence level proficiency, grammar, content development, and genre than voice-related skills. Stapleton's idea that studies of authorial voice bear little theoretical relevance to L2 writing instruction was later reinforced by Helms-Park and Stapleton (2003), who designed a voice intensity rating scale for evaluating voice in L2 texts in terms of assertiveness, self-identification, reiteration of the central idea, and writer presence and autonomy of thought. Their results did not show any correlation between authorial voice intensity and the quality of L2 writings. However, contrary to Helms-Park and Stapleton's (2003) study, Zhao and Llosa (2008), having used the same voice intensity rating scale to L2 texts, found a strong relationship between authorial voices with high intensity and texts with high quality.

To further complicate matters, Matsuda and Tardy (2007) called into question Helms-Park and Stapleton's voice intensity rating scale as it links voice to "the ideology of Western individualism" (p. 236). Later, in her attempts to measure voice strength among L2 writers, Zhao (2013) developed an analytic rubric on the basis of Hyland's (2008) interactional voice model. One part of Hyland's model includes the individualistic aspect of the notion of voice, which pertains to the way writers present themselves and their ideas and arguments by means of linguistic categories like boosters, hedges, attitude markers, and authorial self-mention (the stance dimension). The other part of the model relates to the interdependent aspect of voice, as characterized by the writer's use of linguistic- and discourse-level categories such as reader pronouns, personal asides, references to shared knowledge, directives, and rhetorical/audience directed questions (the engagement dimension). In her following study in 2017, Zhao adopted her own analytic rubric to measure authorial voice strength in L2 and to examine the relationship between voice strength and scores on L2 argumentative writings. Her results revealed that authorial voice was a significant predictor of argumentative essay scores, with each dimension of voice strength (i.e., ideational, affective, and presence dimensions) being strongly or moderately correlated with quality of L2 writings.

Concerning the second reason for understating the role of voice in L2 writing, some researchers in the area of L1 writing (e.g., Elbow, 1999; Holding, 2005; Stewart, 1992) have contended that authorial voice is a purely individual trait and can only be manifested in the writer's essential individuality through individual practices of expressive writing. Extending this notion of individuality, some other researchers have argued that voice in its traditional individualistic sense may be incompatible with some L2 learners' collectivist cultures (Hirvela \& Belcher, 2001; Shen, 1989). For example, 
Shen (1989) made reference to China's collectivist culture, where the first-person singular pronoun "I" is always subordinated to the plural pronoun "We" and associated this fact with Chinese learners' difficulty in constructing their individual voice through composing English essays with singular pronouns. In another study, Ivanič and Camps (2001) analyzed the writings of graduate Mexican students studying in British universities to investigate the way they represent themselves in their writing. Their results showed that Mexican writers of English were generally reluctant to use the firstperson singular pronoun in their writings; instead, they tended to use the agentless passive forms of the verbs in order to be left unknown, while giving more weight to the content.

Be that as it may, as more students from diverse linguistic and cultural backgrounds entered into American universities, the individualistic view of voice was gradually challenged by scholars who believed authorial voice is socially and culturally constructed and mediated. In this respect, Ramanathan and Kaplan (1996) contend that "audience and voice are largely culturally constrained notions, relatively inaccessible to students who are not full participants in the culture within which they are asked to write" (p. 22). Therefore, it follows that the difficulties that L2 writers face in constructing individual voice in the American mainstream culture may be due to their lack of familiarity with the intended audience as well as their lack of shared cultural knowledge in order to meet mainstream expectations of how voice in writing should be manifested. In a study carried out in the Japanese English as a Second Language (ESL) context, Matsuda (2001) provides evidence of individual voice in Japanese written discourse by exploring a Japanese web diary, focusing on some of the distinct linguistic features that are not available in English. Matsuda argues that the difficulties that Japanese learners face in demonstrating their voice in English written discourse do not have much to do with its incompatibility with learners' collectively-oriented cultural values. Rather, lack of individual voice in English writings among Japanese learners can be more associated with the different possibilities that the two languages provide for manifesting authorial voice as well as L2 learners' unfamiliarity with the strategies used for constructing voice in written English.

The idea that inherent differences in cultures can lead to different styles of writing has its roots in Kaplan's (1966) contrastive rhetoric. As Connor (2002) states, contrastive rhetoric is based on the idea that, "to the degree that language and writing are cultural phenomena, different cultures have different rhetorical tendencies" (p. 494). In view of this, while English-speaking writers in the United States tend to adopt a direct and tothe-point approach, L2 writers in Asia are more likely to follow an indirect, talking around-the-point method of organizing their writings (Kaplan, 1990). Moreover, other scholars like Atkinson (1997) and Fox (1994) have argued that Asian learners lack individual voice and the ability to think critically, because these are features peculiar to, and the products of, the Western culture which lead to good writing. These scholars believe that, because Asian learners lack these abilities and are not completely familiar with the American culture, they cannot display this kind of thinking in their writings. 
However, other researchers (e.g., Davidson \& Dunham, 1997; Stapleton, 2001; Wu \& Rubin, 2000) have investigated the case in some Asian countries like China and Japan and have refused to accept the idea that Asian students are deficient in individual voice or critical thinking skills. For example, Stapleton (2001) investigated the case among Japanese learners and found that these learners do have the ability to think critically, provided that the topic content is familiar to them. Other researchers have also put the act of stereotyping Chinese learners as passive, rote learners into serious question (e.g., Biggs, 1996), and have further ascribed the Chinese students' difficulties in topic development, expressiveness and, generally, composing well-developed arguments to the cultural differences between China and the West (e.g., Hofstede, 1986).

\subsection{Purpose of the present study}

Given the information above, one may conclude that the handful of existing empirical studies in different L2 contexts on the importance of voice in L2 writing as well as studies on the existence or non-existence of individual voice among Asian learners of English have provided contradictory results. In view of this, it seems that more research on authorial voice in other L2 contexts is needed. To fill this gap, the present study sought to examine (a) the general level of voice strength among L2 writers in the Iranian English as a Foreign Language (EFL) context, and (b) the relationship between Iranian L2 learners' authorial voice strength and the quality of their argumentative written task performances. In addition, the authors sought to investigate whether the three voice dimensions have different difficulty levels and whether they function differently for the two genders. Therefore, this study mainly seeks to answer the following five research questions:

1. What is the level of voice strength in L2 argumentative writings among Iranian learners of English?

2. Are the three dimensions (ideational, affective, presence) of authorial voice associated with the overall quality of L2 argumentative writings?

3. Is the overall authorial voice strength associated with the overall quality of L2 argumentative writings?

4. Is there any significant difference in the difficulty level of the three dimensions of voice?

5. Is there any Differential Item Functioning (DIF) in the examination of the three voice dimensions between participants from two genders?

\section{Method}

\subsection{Setting and Participants}

To avoid confounding learners' English language proficiency with the quality of their L2 writing task performance and to assure that the sample selected for the study was 
relatively homogeneous concerning L2 proficiency, a version of Oxford Placement Test (OPT) was used. The test consisted of grammar (20 items), vocabulary (20 items), reading comprehension (20 items), and a writing section. Out of a pool of 165 learners, 36 were excluded from participation in the study because their scores on the OPT were either below or above the specified upper-intermediate B2 level (score range: 61-80) based on the Common European Framework of Reference for Languages (CEFR). Finally, a sample of 129 homogeneous upper-intermediate L2 learners was obtained for further participation in the study. We recruited upper-intermediate learners because they were required to develop an argumentation of at least 250 words about a hotly debated issue. They were recruited from six writing courses from three universities in Neyshabur, a city in the northeast of Iran. The sample included 97 females (75.2\%), 32 males $(24.8 \%)$. Prior to participating in the study all learners provided informed consent for extra course credit. All Learners were native speakers of Persian and were studying English as an academic major (English Language and Literature, Teaching English as a Foreign Language, and English Translation Studies). The participants' mean age was $19.9(S D=1.3$, range: $18-26)$. Age information was missing for 6 participants.

\subsection{Instrumentation}

To address the research questions suggested above, along with an argumentative writing task, two other instruments were required: one which measured the different aspects of authorial voice strength, and the other which assessed the overall quality of a written passage.

\subsubsection{Argumentative writing task}

The writing prompt in this study came in the form of a debate topic. Writing samples requiring participants to argue in favor of or against the increasing rate of girls attending university were elicited from learners. More specifically, learners were provided with a two-sided debate: "There are some people who argue that too many girls go to university, while others claim that university education should be a universal right." Learners were expected to discuss both sides of the argument and finally give their own opinion. An argumentative task was used in the present study, because in this genre the writers are typically prompted to express their personal opinions on a controversial topic, to convince others to see things their way, and sometimes to encourage them to take actions (Hirose, 2003), hence enabling learners to manifest, and make better use of, their authorial voice. Having conducted a pilot study on 12 upper-intermediate L2 learners, the researchers came up with an average time of 32 minutes for the completion of the task.

\subsubsection{The analytic voice rubric}

In order to measure authorial voice strength, we used Zhao's (2013) analytic voice rubric (see Appendix A). In developing the rubric, Zhao followed Hyland's (2008) 
theoretical model that regards authorial voice as (1) the extent to which the writer and the reader interact through various textual functions and features such as, inter alia, hedges, boosters, attitude markers and self-mention, and (2) the degree to which the writer engages the reader through the use of reader pronouns, references to shared knowledge, personal asides, directives, and questions. In this respect, Zhao's (2013) analytic voice rubric consists of three dimensions that were measured on a scale from 1 to 5: (a) the ideational dimension that considers the presence, clarity, and full development of ideas as well as the uniqueness and sophistication of a central point in the text; (b) the affective dimension which refers to particular language use that shows authority and confidence in the presentation of ideas and claims, indicates a clear stance on the topic under discussion, adds personality and life to the writing, and is sophisticated and eye-catching to the intended reader; and (c) the presence dimension evaluated voice in terms of whether the writers are able to give readers a clear sense of who they are as unique individuals, and whether the writers can effectively engage readers throughout the writing and interact with them through sharing their personal experiences. In addition to these analytic ratings of voice, both raters were asked to provide a holistic rating of overall authorial voice strength in written argumentations on a scale from 1 to 5 ( 1 = almost absent voice; $5=$ very strong voice).

\subsubsection{Rubric for measuring writing quality}

In order to assess the overall quality of learners' writings, each sample of writing was rated by two trained raters, using the TOEFL scoring rubric. Moreover, at times when there was a misunderstanding on the part of the two raters and scores differed by more than one point, a third rater stepped in and clarified the misunderstanding. The rubric measures writing on a scale from 1 to 5 based on four components of topic relevance, content development, organization and coherence, and language use (see Appendix B).

\subsection{Procedure}

Data collection took place within five weeks in the second-half of the Iranian academic year (April - May 2018). The researchers met the participants in classrooms and provided them with brief information about the research project. The participants were told about how to complete the argumentative writing task as well as the expected length of the writings; however, no information was given regarding issues of authorial voice. They were informed that the decision to take part in this study would be completely voluntary, and that the data collected from them would be kept confidential and used only for research purposes. Moreover, in order to provide anonymity of information collected from the participants, each learner was assigned a code that included the last four digits of their student ID numbers.

To measure learners' authorial voice strength as well as the quality of their argumentations, two validated rubrics were used. Having scored all argumentations, the first rater submitted all writing samples to another rater, a Ph.D. student of English 
teaching at University of Tehran, Iran. In order to measure inter-rater agreement, the second rater was asked to score writings for authorial voice and writing quality by following the same rubrics used in this study. Inter-rater reliability, based on the Spearman-Brown Prophecy Formula, was found to be high (.90 for the holistic rating of voice strength, .95 for the ideational dimension, .89 for the affective dimension, .86 for the presence dimension, and .86 for writing quality). Finally, considering the fact that some of the scores given by the two raters differed, the decision about which score to use for conducting the analysis was made based on the discussion between the two raters. In this connection, discussion has been regarded as a reliable method of resolving score differences in the rating of writing samples (e.g., Johnson, Penny, Gordon, Shumate, \& Fisher, 2005; Johnson, Penny, \& Johnson, 2000).

To analyze the data, two statistical software packages were used. To investigate the correlations among the variables and the predictive power of voice dimensions, SPSS (version 21 - IBM, 2012) was used. Moreover, Winsteps (2016) was used for examining the item difficulty of voice assessment rubric and examining the DIF of these items.

\section{Results}

Table 1 presents the descriptive statistics for the voice ratings and the writing task. As shown, the average score that the participants received on the argumentative writing task was 2.48 out of $5(\mathrm{SD}=.81)$. Moreover, the means for the rest of the voice variables ranged between 1.27 (for the presence dimension) and 2.49 (for the ideational dimension) (on a scale from 1 to 5), with standard deviations ranging from .55 to .89. Therefore, as regards the first research question "What is the level of voice strength in L2 argumentative writings among Iranian learners of English?", while all of the items were examined on a 5-point Likert scale, none of them reached the maximum of the range (i.e., 5). Moreover, while the affective dimension and total voice reached the maximum of 4 and 3 respectively, their means were less than 2 . Further, the mean of writer presence was around 1, which is considered the minimum value in their range. These findings indicate that only some of the participants had strong voice and the majority of them were weak regarding the aforementioned elements (see Appendix C for a sample of an argumentative writing with concrete examples of the presence/absence of voice dimensions).

Table 1. Descriptive Statistics for the Voice Ratings and Argumentative Writing Scores $(N=129)$

\begin{tabular}{lllll}
\hline & Min & Max & $M$ & \multicolumn{2}{c}{$S D$} \\
\hline Dimension 1 (ideational) & 1.00 & 4.00 & 2.49 & .76 \\
Dimension 2 (affective) & 1.00 & 4.00 & 1.99 & .89 \\
Dimension 3 (presence) & 1.00 & 3.00 & 1.27 & .55 \\
Total voice & 1.00 & 4.00 & 1.82 & .87 \\
Writing quality & 1.00 & 4.00 & 2.48 & .81 \\
\hline
\end{tabular}


For answering the second research question (Are the three dimensions of authorial voice associated with the overall quality of L2 argumentative writings?), a Pearson Product-Moment correlation analysis between L2 argumentative essay scores and authorial voice components was run. As Table 2 shows, the results revealed a statistically significant positive correlation $(r=.57, p<.01)$ between the total voice strength of learners and the quality of their writings. Moreover, when examined in isolation, each voice dimension was significantly and positively correlated with the quality of argumentations. More specifically, there were strong correlations between L2 argumentative writing quality and voice as captured by the affective dimension (D2) ( $r$ $=.54, \mathrm{p}<.01)$, followed by the ideational dimension (D1) $(r=.46, p<.01)$ and the presence dimension (D3) $(r=.40, p<.01)$.

Table 2. Correlation Matrix: Dimensional Voice Ratings and Argumentative Writing Scores

\begin{tabular}{llllll}
\hline & WS & TV & D1 & D2 & D3 \\
\hline WS (writing scores) & - & $.57^{* *}$ & $.46^{* *}$ & $.54^{* *}$ & $.40^{* *}$ \\
TV (total voice) & & - & $.64^{* *}$ & $.88^{* *}$ & $.78^{* *}$ \\
D1 (ideational dimension) & & - & $.54^{* *}$ & $.44^{* *}$ \\
D2 (affective dimension) & & & - & $.71^{* *}$ \\
D3 (presence dimension) & & & & - \\
\hline
\end{tabular}

Note: ${ }^{* *}$ Correlation is significant at the .01 level (2-tailed).

Next, to see whether authorial voice dimensions can predict the overall quality of argumentations, a multiple regression analysis (MRA) was run. Before running the regression, the assumptions of parametric tests (Pallant, 2013) including normality, linearity, homoscedasticity and independence of residuals were tested and met. Results from MRA indicated that the overall model was statistically significant, $\mathrm{R}^{2}=.32, \mathrm{~F}(3$, $125)=20.98, p<.001$. Moreover, the results showed that two dimensions of voice (i.e., ideational and affective dimensions) can significantly predict the overall quality of L2 argumentative writings. In other words, although when examined in isolation, each dimension of voice was significantly and positively correlated with the quality of argumentations, further regression analysis showed that the affective and ideational dimensions were statistically significant predictors of writing quality. As can be seen in Table 3, these two voice dimensions could explain about $32 \%$ of the total variance in argumentative writing scores.

Moreover, in order to answer the third research question (Is the overall authorial voice strength associated with the overall quality of L2 argumentative writings?), the obtained holistic scores of the two variables (i.e., writing and voice) were codified into three categories: Low $(0-1.66)$, mid $(\geq 1.67-3.33)$ and high $(\geq 3.34-5)$. 
Table 3. Predicting Argumentative Writing Scores from Voice Dimensions $(\mathrm{N}=129)$

\begin{tabular}{cccccc}
\hline Model & $R$ & $R^{2}$ & Adjusted $R^{2}$ & $S E$ & $p$ \\
\hline & $.54^{\mathrm{a}}$ & .29 & .28 & .68 & $<.001$ \\
2 & $.57^{\mathrm{b}}$ & .33 & .32 & .66 & $<.001$ \\
\hline
\end{tabular}

a. Predictors: (Constant), dimension 2; b. Predictors: (Constant), dimension 2, dimension 1

Next, a Multiple Correspondence Analysis (MCA) was run, and the significance of dependencies was checked ( $p$-value <.05). MCA is an explanatory method used to analyze categorical data (Benzecri, 1992), while enabling the researcher to display graphically complicated numerical tables (Hoffman \& Franke, 1986). Once it was confirmed that there was a link between the categories of the variables, the dimensionality of the solution was analyzed, and the proper number of dimensions was determined equal to two factors with an almost $62 \%$ accurate categorization. In this respect, Figure 1 suggests that there are two groups of association between the variables. Group A shows that low and mid writing proficiency are associated with low voice ability; that is, those learners whose writing proficiency is either low or mid do not show high voice in their argumentative writings. Moreover, group B shows that high and mid voice strength mainly exist in learners with high writing proficiency. In other words, students may not show high voice in their argumentative writings until they gain high proficiency in writing.

In order to answer the fourth and fifth research questions, which asked about the difficulty level of the three voice dimensions and whether they function differently for the two genders, a set of IRT and DIF analyses were run, respectively. First, in order to find the normality of the data, the fit indices (i.e., infit and outfit) were checked, and no unexpected pattern of performance was found for the three voice dimensions. That is to say, all participants had a normal performance on authorial voice. In terms of difficulty, the presence dimension was shown to be the most difficult dimension with 4.59 logits difficulty level. It was followed by the ideational dimension and the affective dimension with -0.22 and -2.54 logits difficulty levels, respectively. In other words, while the affective dimension was shown to be the easiest aspect of authorial voice, our participants were least capable of showing their presence as an author in their argumentations.

Next, a DIF analysis was run to examine the invariance of the measurement across participants. When an item shows DIF, it has different statistical properties across different groups of participants. Therefore, in the present study a DIF analysis was done to see whether the dimensions of authorial voice are at the same level of difficulty for both genders. As can be seen in Table 5, although the DIF measures showed that the three voice dimensions were more difficult for men, given that all $p$ values were more than .05, it can be said that none of the dimensions showed DIF in our analysis, and they functioned similarly for the two genders. 


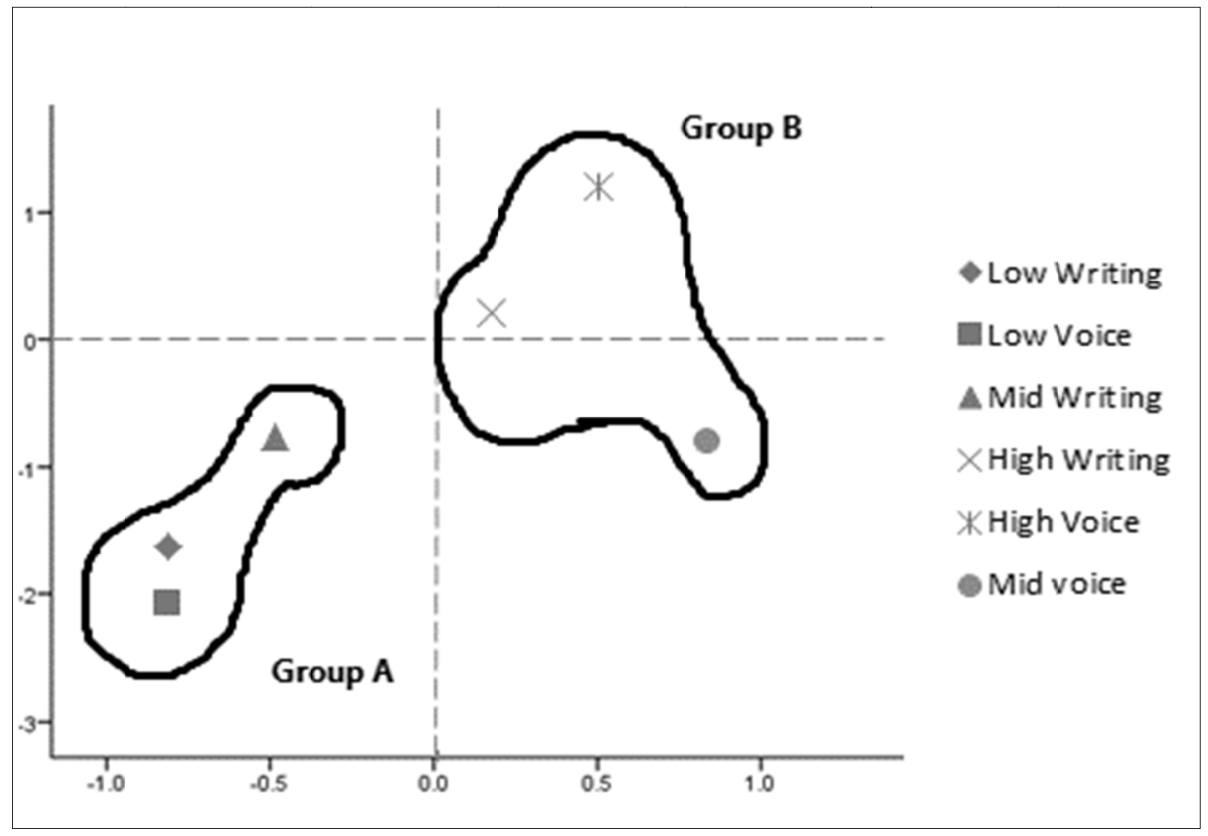

Figure 1. Joint description of authorial voice and quality of writing.

Table 4. IRT Analysis of Voice Dimensions

\begin{tabular}{lllllllll}
\hline & & & & & \multicolumn{3}{c}{ INFIT } & \multicolumn{2}{c}{ OUTFIT } \\
\cline { 6 - 9 } Item & Total & Total & Measure & Model & MNSQ & ZSTD & MNSQ & ZST \\
& Score & Count & & S.E. & & & & D \\
\hline Affective & 321 & 129 & -2.54 & .19 & 1.25 & 1.9 & 1.32 & 1.3 \\
$\begin{array}{l}\text { Dimension } \\
\text { Ideational }\end{array}$ & 257 & 129 & -.22 & .20 & .77 & -1.9 & .69 & -2.2 \\
$\begin{array}{l}\text { Dimension } \\
\begin{array}{l}\text { Presence } \\
\text { Dimension }\end{array}\end{array}$ & 164 & 129 & 4.59 & .30 & .90 & -.4 & .43 & -.7 \\
\hline
\end{tabular}


Table 5. DIF Analysis of Voice Dimensions across Genders

\begin{tabular}{|c|c|c|c|c|c|c|c|}
\hline \multirow[t]{2}{*}{ Item } & \multirow{2}{*}{$\begin{array}{l}\text { Person } \\
\text { Group }\end{array}$} & \multirow{2}{*}{$\begin{array}{l}\text { DIF } \\
\text { Measure }\end{array}$} & \multirow{2}{*}{$\begin{array}{l}\text { Person } \\
\text { Group }\end{array}$} & \multirow{2}{*}{$\begin{array}{l}\text { DIF } \\
\text { Measure }\end{array}$} & \multicolumn{3}{|c|}{ Rasch-Welch } \\
\hline & & & & & $t$ & $d f$ & $p$ \\
\hline Affective Dimension & Male & -2.30 & Female & -2.62 & .73 & 53 & .46 \\
\hline $\begin{array}{l}\text { Ideational } \\
\text { Dimension }\end{array}$ & Male & -.15 & Female & -.24 & .20 & 52 & .84 \\
\hline Presence Dimension & Male & 4.98 & Female & 4.41 & .90 & 61 & .37 \\
\hline
\end{tabular}

\section{Discussion}

Writing with strong voice is a valuable trait in the American mainstream culture and, in the past two decades, it has been used in evaluating students' writing performance. However, when it comes to L2 writing, the question of whether or not voice plays any role in L2 writing has not elicited unanimous responses. In an effort to fill this gap, in the present study we examined the level of voice strength among Iranian L2 writers and investigated the relationship between L2 learners' authorial voice strength and the quality of their argumentative written task performances.

Our findings revealed that the Iranian writers who constituted our sample generally demonstrated a low level of individual voice strength in their argumentations. This finding agrees with previous empirical research (e.g., Hirvela \& 'Belcher, 2001; Shen, 1989) showing that L2 learners, particularly those from collectivist cultures, tend to face more difficulty in writing with a strong voice. Part of this problem seems to have developed due to a general tendency of Iranian learners to confine themselves to the ideas presented in their course books at school or university, while accepting the ideas presented in the texts or the information that the teachers 'transfer'. Moreover, among the three voice dimensions used in our study, the 'presence' dimension has proved to be the most difficult one. That is, the participants in our sample were least capable of revealing themselves as unique individuals in their writings. Moreover, they have been unable to engage the readers effectively in their argumentations and to relate the subject appropriately to their personal backgrounds and experiences. This finding is in line with that of another study conducted in the Iranian context (Zare-ee, Hematiyan, \& Matin, 2014) in which undergraduate L2 learners were reluctant to use first-person singular pronouns and an active voice for identifying themselves in their argumentations. As Salmani Nodoushan (2016) argues, Iranian learners lack the ability of self-representation by integrating their own ideas in English writing. When asked to write about a given topic, they typically regurgitate back the 'previously-received' information on paper with little sense of being independent writers. One reason to explain this can be the fear Iranian learners normally have of being judged or questioned which, in turn, may have stemmed from their collectivist cultural values.

Therefore, one possible explanation for the lack of authorial voice among Iranian L2 writers could be sought in cultural differences. In fact, research focusing on the Iranian 
writers of English has been characterized by a contrast between Iranian and English cultures. For example, in their attempts to investigate the use of some indirectness devices such as thesis statement, rhetorical question, irony, hedges, the passive voice, and conditional tense in Persian (the native language of Iranians) and English argumentative essays, Alijanian and Dastjerdi (2012) found that Iranian writers made more frequent use of indirect devices than their English counterparts. They further argued that, unlike English writers who tend to adopt a direct and straightforward approach for conveying information to readers, Iranian writers mostly adopt an inductive and indirect approach to writing arguments, which is in contrast with the individualistic perspective of voice. In this respect, Pishghadam and Attaran (2012) have shown that Iranian L2 writers transfer the rhetorical patterns of their L1 argumentation to their L2 writing, implying that the indirectness which is highly admired in the Iranian culture could determine the argumentation elements to be presented in L2 compositions. The indirectness that encompasses Iranian writers' expressions is intended to achieve respect and harmony in human communication (Alijanian \& Dastjerdi, 2012). It follows that directly expressing ideas could mean disrespecting the readers in the Iranian culture. In a similar line, Shokouhi and Baghsiahi (2010) have argued that Persian is a reader responsible language in which writers leave room for readers to interpret.

While L2 learners in the present study generally demonstrated a low level of voice strength in their argumentations, our results revealed that the three dimensions of authorial voice functioned similarly (were at the same level of difficulty) for both genders. This finding clearly contradicts Connors' (1995) assertion that the entrance of women into higher education has led to the decline of rhetoric and debate in argumentation. Our finding, on the other hand, supports Zare-ee at al.'s (2014) study on Iranian L2 learners' argumentative writings in which no gender-related differences were found in the mean score of authorial voice components.

Furthermore, the present study found that there were strong positive correlations between learners' writing quality and the three dimensions of voice. Results from regression analysis suggested positive associations between two dimensions of voice strength and the quality of learners' writings. More specifically, affective and ideational voice dimensions accounted for about one-third (i.e., 32\%) of the variance in argumentative writing scores, suggesting that voice is statistically significantly associated with writing quality. This finding shows that in the context of L2 argumentative writing, the clear presentation of an eye-catching and sophisticated idea as well as showing authority and confidence in argument presentation are the cornerstones of the act of voice-construction and can be important factors that contribute to raters' positive evaluation of the quality of L2 argumentative writings. Furthermore, results from multiple correspondence analysis pointed to the association of low- and mid-level writing quality and low voice strength. Put another way, those learners whose writing proficiency was at either low or average level could not demonstrate high strength voice in their argumentations. Moreover, the results showed 
the prevalence of high and average voice strength mostly in learners with high proficiency in writing. In view of this, it can be concluded that learners may not be able to demonstrate high authorial voice in their argumentations until they gain high proficiency in writing.

While supporting studies which pointed to the significant role of voice in L2 writing quality (Zhao, 2013; Zhao \& Llosa, 2008), our findings appear to contradict the studies conducted by Stapleton (2002) and Helms-Park and Stapleton (2003) who did not find any relationship between authorial voice and the quality of L2 writings. The reason for such disparity in results may lie in the fact that to measure learners' authorial voice, both Stapleton (2002) and Helms-Park and Stapleton (2003) have used a voice intensity rating scale that merely includes the individualistic aspect of voice. In the present study, however, we used Zhao's (2013) analytic voice rubric that is primarily developed based on Hyland's (2008) interactional voice model which incorporates both individualistic and interdependent aspects of the notion of voice.

\section{Conclusion}

Taken together, given the belief that L2 writers with collectivist cultures tend to face more difficulty in writing with a strong voice that can be appreciated by audience from the mainstream culture, some might argue, therefore, that researchers and practitioners in the area of L2 writing should not give voice more attention than it deserves and that they should not let the discussion of voice "take precedence over ideas and argumentations" (Stapleton, 2002, p. 177). Be that as it may, a combination of the findings of the present study that Iranian writers lack a strong authorial voice in their writings and that the affective and ideational dimensions of voice turned out to be statistically significant predictors of L2 argumentative writing quality highlights the importance of teaching voice to L2 student writers. To achieve this aim, scholars and researchers in the area of L2 writing can shift their discussions to how L2 writing programs and instructors can better help learners who live in collectivist cultures succeed in dealing with the highly demanding challenge of trying to develop a voice of one's own and, ultimately, constructing a strong authorial voice. However, the majority of studies to date have focused on how to measure voice and assess its role in writing quality but, to the best of our knowledge, there is no empirical proposal on how to design L2 writing programs that promote authorial voice. Aside from the lack of a strong authorial voice among Iranian L2 writers, another important point here is that text quality was generally poor among our participants. This result may be due to the way English is taught in the Iranian Educational system, where the focus is more on developing oral skills (Zabihi, 2018), unless students attend intensive training programs to better perform on the writing tasks of international English tests.

It is worth noting that the study reported in this paper has four limitations. Although these limitations can offer opportunities for further research, the findings of the present study need to be interpreted with some caution. First, in this study we adopted one 
specific operational definition of voice to examine learners' voice strength. In view of this, the results of studies that would take other approaches to the assessment of authorial voice might be different. Second, the findings of this study may also be affected by the kind of writing task as well as the rubric which is adopted for assessing writing quality. In this study, we administered an argumentative writing task and used the TOEFL scoring rubric for assessing text quality. Therefore, it seems safe to assume that researchers using other writing tasks and measures of writing quality might come up with differing results regarding the association of authorial voice and writing quality. In view of these, it remains to be seen whether and to what extent voice affects the quality of writing in different writing tasks. Third, the focus of the present study was on voice in English L2 writing in a collectivist culture. We concluded that the results agreed with findings that L2 learners from collectivist cultures would face more difficulty in writing with a strong voice, yet the difficulty may in fact be a feature of L2 writing regardless of cultural background. Therefore, other researchers are encouraged to carry out comparative research on learners from both collectivist and individualist cultures, following the same theory and using the same scoring rubrics, and to discuss whether and to what extent voice strength in writing depends on learners' cultural background. Fourth, in the present study we used a quantitative method to investigate the relationship between authorial voice and writing quality. As a result, our study is unable to explain, using qualitative data, how a strong or weak authorial voice on the part of a particular learner may influence the raters' perceptions of text quality. Therefore, a considerable challenge for future research will be to expand the scope of this study by collecting qualitative data from raters on the significance of authorial voice strength in molding their perceptions of L2 writing quality.

\section{Acknowledgements}

We would like to thank Professor Judy Parr, the editor of the Journal of Writing Research (JoWR), and three anonymous reviewers for their careful and constructive reviews of this paper and for providing us with generous feedback and insightful comments, as these led us to an improvement of the work.

\section{References}

Alijanian, E., \& Dastjerdi, H. (2012).The use of indirectness devices in Persian and English argumentative written discourse: A cross-cultural perspective. International Journal of Linguistics, 4(3), 60-70. doi:10.5296/ijl.v4i3.1733

Atkinson, D. (1997). A critical approach to critical thinking in TESOL. TESOL Quarterly, 31, 7194. doi:10.2307/3587975

Atkinson, D. (2001). Reflections and refractions on the JSLW special issue on voice. Journal of Second Language Writing, 10, 107-124. doi:10.1016/S1060-3743(01)00035-2

Bakhtin, M. M. (1981). The dialogic imagination. Austin, TX: University of Texas Press.

Bakhtin, M. M. (1986). Speech genres and other late essays. Austin, TX: University of Texas Press. 
Benzecri, J. P. (1992). Correspondence analysis handbook. New York, NY: Marcel Decker. doi: $10.1201 / 9780585363035$

Biggs, J. B. (1996). Western misperceptions of the Confucian heritage learning culture. In D. A. Watkins \& J. B. Biggs (Eds.), The Chinese learner: Cultural, psychological, and contextual influences (pp. 45-67). Hong Kong: Comparative Education Research Centre.

Bowden, D. (1999). The mythology of voice. Portsmouth, NH: Heinemann.

Cappello, M. (2006). Under construction: Voice and identity development in writing workshop. Language Arts, 83(6), 482-491.

Connor, U. (2002). New directions in contrastive rhetoric. TESOL Quarterly, 36, 493-510. doi: $10.2307 / 3588238$

Connors, R. J. (1995). Women's reclamation of rhetoric in nineteenth-century America. In L. W. Phelps \& J. Emig (Eds.), Feminine principles and women's experience in American composition and rhetoric (pp. 67-90). Pittsburgh, PA: University of Pittsburgh Press.

Davidson, B. W., \& Dunham, R. A. (1997). Assessing EFL student progress in critical thinking with the Ennis-Weir Critical Thinking Essay Test. (ERIC Document Reproduction Service No. ED440550).

Ede, L. (1989). Work in progress: A guide to writing and revising. New York, NY: St. Martin's Press.

Elbow, P. (1981). Writing with power. New York, NY: Oxford University Press.

Elbow, P. (1999). Individualism and the teaching of writing: Response to Vai Ramanathan and Dwright Atkinson. Journal of Second Language Writing, 8(3), 327-338. doi:10.1016/S10603743(99)80120-9

Elbow, P. (2007). Reconsiderations: Voice in writing again: Embracing contraries. College English, 70(2), 168-188. doi:10.2307/25472259

Farmer, F. (1995). Voice reprised: Three etudes for a dialogic understanding. Rhetoric Review, 13(2), 301-320. doi:10.1080/07350199509359189

Flower, L., \& Hayes, J. (1980). The dynamics of composing: Making plans and juggling constraints. In L. Gregg \& E. Steinberg (Eds.), Cognitive processes in writing (pp. 31-50). Hillsdale, NJ: Lawrence Erlbaum.

Fox, H. (1994). Listening to the world: Cultural issues in academic writing. Urbana, IL: National Council of Teachers of English.

Hayes, J. R., \& Gradwohl Nash, J. (1996). On the nature of planning in writing. In C. M. Levy \& S. E. Ransdell (Eds.). The science of writing: Theories, methods, individual differences and applications (pp. 29-55). Mahwah, NJ: Lawrence Erlbaum.

Helms-Park, R., \& Stapleton, P. (2003). Questioning the importance of individualized voice in undergraduate L2 argumentative writing: An empirical study with pedagogical implications. Journal of Second Language Writing, 12(3), 245-265. doi:10.1016/j.jslw.2003.08.001

Hillocks, G. J. (1995). Teaching writing as reflective practice. New York, NY: Teacher College Press.

Hirose, K. (2003). Comparing L1 and L2 organizational patterns in the argumentative writing of Japanese EFL students. Journal of Second Language Writing, 12, 181-209. doi:10.1016/S10603743(03)00015-8

Hirvela, A., \& Belcher, D. (2001). Coming back to voice: The multiple voices and identities of mature multilingual writers. Journal of Second Language Writing, 10(1-2), 83-106. doi:10.1016/S1060-3743(00)00038-2

Hoffman, D. L., \& Franke, G. R. (1986). Correspondence analysis: Graphical representation of categorical data in marketing research. Journal of Marketing Research, 23, 213-227. doi:10.1177/002224378602300302

Hofstede, G. (1986). Cultural differences in teaching and learning. International Journal of Intercultural Relations, 10, 301-320. doi: 10.1016/0147-1767(86)90015-5

Hofstede, G. (2001). Culture's consequences: Comparing values, behaviors, institutions, and organizations across nations. Thousand Oaks, CA: Sage.

Holding, M. (2005). Liberating the student's voice: A teacher's story of the college essay. English Journal, 94(4), 76-82. doi:10.2307/30046464 
Hyland, K. (2002). Options of identity in academic writing. ELT Journal, 56(4), 351-358. doi:10.1093/elt/56.4.351

Hyland, K. (2008). Disciplinary voices: Interactions in research writing. English Text Construction, 1(1), 5-22. doi:10.1075/etc.1.1.03hyl

Hyland, K. (2010). Community and individuality: Performing identity in applied linguistics. Written Communication, 27(2), 159-188. doi:10.1177/0741088309357846

Ivanič, R., \& Camps, D. (2001). I am how I sound: Voice as self-representation in L2 writing. Journal of Second Language Writing, 10(1-2), 3-33. doi:10.1016/S1060-3743(01)00034-0

Jeffery, J. (2009). Constructs of writing proficiency in US state and national writing assessments: Exploring variability. Assessing Writing, 14(1), 3-24. doi:10.1016/j.asw.2008.12.002

Johnson, R. L., Penny, J., Gordon, B., Shumate, S. R., \& Fisher, S. P. (2005). Resolving score differences in the rating of writing samples: Does discussion improve the accuracy of scores? Language Assessment Quarterly: An International Journal, 2(2), 117-146. doi: 10.1207 /s15434311laq0202_2

Johnson, R. L., Penny, J., \& Johnson, C. (2000, April). A conceptual framework for score resolution in the rating of performance assessments: The union of validity and reliability. Paper presented at the annual meeting of the American Educational Research Association, New Orleans, LA.

Johnstone, B. (2000). The individual voice in language. Annual Review of Anthropology, 29, 405424.doi: 10.1146/annurev.anthro.29.1.405

Kaplan, R. B. (1966). Cultural thought patterns in inter-cultural education. In T. Silva \& P. K. Matsuda (Eds.), Landmark essays on ESL writing (pp. 11-25). Mahwah, NJ: Erlbaum.

Kaplan, R. B. (1990). Writing in a multilingual/multicultural context: What's contrastive about contrastive rhetoric? The Writing Instructor, 10(1), 7-18.

Llosa, L., Beck, S. W., \& Zhao, C. G. (2011). An investigation of academic writing in secondary schools to inform the development of diagnostic classroom assessments. Assessing Writing, 16, 256-273. doi:10.1016/j.asw.2011.07.001

Matsuda, P. K. (2001). Voice in Japanese written discourse: Implications for second language writing. Journal of Second Language Writing, 10(1-2), 35-53. doi:10.1016/S10603743(00)00036-9

Matsuda, P. K., \& Jeffery, J. V. (2012). Voice in student essays. In K. Hyland \& C. S. Guinda (Eds.), Stance and voice in written academic genres (pp. 151-156). Basingstoke, UK: Palgrave Macmillan. doi:10.1057/9781137030825_10

Matsuda, A., \& Matsuda, P. K. (2010). World Englishes and the teaching of writing. TESOL Quarterly, 44(2), 369-374. doi:10.5054/tq.2010.222222

Matsuda, P. K., \& Tardy, C. M. (2007). Voice in academic writing: The rhetorical construction of author identity in blind manuscript review. English for Specific Purposes, 26, 235-249. doi:10.1016/j.esp.2006.10.001

Pallant, J. (2013). SPSS survival manual. London, UK: McGraw-Hill Education.

Pishghadam, R., \& Attaran, A. (2012). Rhetorical patterns of argumentation in EFL journals of Persian and English. International Journal of Research Studies in Language Learning, 2(1), 110. doi:10.5861/ijrsll.2012.132

Prior, P. (2001). Voice in text, mind, and society: Sociohistoric accounts of discourse acquisition and use. Journal of Second Language Writing, 10(1-2), 55-81. doi:10.1016/S10603743(00)00037-0

Ramanathan, V., \& Atkinson, D. (1999). Individualism, academic writing, and ESL writers. Journal of Second Language Writing, 8(1), 45-75. doi:10.1016/S1060-3743(99)80112-X

Ramanathan, V., \& Kaplan, R. B. (1996). Audience and voice in current L1 composition texts: Some implications for ESL student writers. Journal of Second Language Writing, 5(1), 21-34. doi:10.1016/S1060-3743(96)90013-2

Riyanti, D. (2015). An exploration of voice in second language writing. The Nebraska Educator, 2, $28-48$. 
Saboori, F., Pishghadam, R., Fatemi, A. H., \& Ghonsooli, B. (2015). Culture and identity: Linking Iranian identity components and cultural dimensions. Issues in Language Teaching, 4(1), 4978. doi:10.22054/ilt.2015.3463

Salmani Nodoushan, M. A. (2016). Working on the 'write' path: Improving EFL students' argumentative-writing performance through L1-mediated structural cognitive modification. International Journal of Language Studies, 10(4), 131-152.

Scardamalia, M. (1981). How children cope with the cognitive demands of writing. In C. H. Frederiksen \& J. F. Dominic (Eds.), Writing: The nature, development, and teaching of written communication (pp. 81-103). Hillsdale, NJ: Lawrence Erlbaum.

Shen, F. (1989). The classroom and the wider culture: Identity as a key to learning English composition. College Composition and Communication, 40(4), 459-466. doi: 10.2307/ 358245

Shokouhi, H., \& Baghsiahi, A. T. (2009). Metadiscourse functions in English and Persian sociology articles: A study in contrastive rhetoric. Poznan Studies in Contemporary Linguistics, 45(4), 549-568. doi:10.2478/v10010-009-0026-2

Sperling, M., Appleman, D., Gilyard, K., \& Freedman, S. (2011). Voice in the context of literacy studies. Reading Research Quarterly, 46(1), 70-84. doi:10.1598/RRQ.46.1.4

Stapleton, P. (2001). Assessing critical thinking in the writing of Japanese university students: Insights about assumptions and content familiarity. Written Communication, 18(4), 506-548. doi:10.1177/0741088301018004004

Stapleton, P. (2002). Critiquing voice as a viable pedagogical tool in L2 writing: Returning spotlight to ideas. Journal of Second Language Writing, 11(3), 177-190. doi:10.1016/S10603743(02)00070-X

Stewart, D. C. (1972). The authentic voice: A pre-writing approach to student writing. Dubuque, IA: Brown.

Stewart, D. C. (1992). Cognitive psychologists, social constructionists, and three nineteenthCentury advocates of authentic voice. Journal of Advanced Composition, 12(2), 279-290.

Wu, S. Y., \& Rubin, D. L. (2000). Evaluating the impact of collectivism and individualism on argumentative writing by Chinese and North American college students. Research in the Teaching of English, 35(2), 148-178.

Yancey, K. B. (1994). Introduction: Definition, intersection, and difference - mapping the landscape of voice. In K. B. Yancey (Ed.), Voices on voice: Perspectives, definitions, inquiry (pp. vii-xxiv). Urbana, IL: National Council of Teachers of English.

Yeh, S. S. (1998). Validation of a scheme for assessing argumentative writing of middle school students. Assessing Writing, 5(1), 123-150. doi:10.1016/S1075-2935(99)80009-9

Zabihi, R. (2018). The role of cognitive and affective factors in measures of L2 writing. Written Communication, 35(1), 32-57. doi:10.1177/0741088317735836

Zare-ee, A., Hematiyan, N., \& Matin, S. A. (2014). Voice in short argumentative texts written by undergraduate learners of English. The Journal of Teaching Language Skills, 6(1), 93-111. doi:10.22099/jtls.2014.2025

Zhao, C. G. (2013). Measuring authorial voice strength in L2 argumentative writing: The development and validation of an analytic rubric. Language Testing, 30(2), 201-230. doi:10.1177/0265532212456965

Zhao, C. G. (2017). Voice in timed L2 argumentative essay writing. Assessing Writing, 31, $73-83$. doi:10.1016/j.asw.2016.08.004

Zhao, C. G., \& Llosa, L. (2008). Voice in high-stakes L1 academic writing assessment: Implications for L2 writing instruction. Assessing Writing, 13(3), 153-170. doi:10.1016/j.asw.2008.10.003 
351 | JOURNAL OF WRITING RESEARCH

\section{Appendix A: The Analytic Voice Rubric}

\begin{tabular}{ll}
\hline Ideational Dimension & $\begin{array}{l}\text { Voice Evoked by the Presence and Clarity of Ideas in the } \\
\text { Content }\end{array}$
\end{tabular}

- The reader feels a clear presence of a central idea (point of view) throughout the text.

- The writing shows a strong commitment to the topic through full development of the central idea (point of view) with adequate use of effective examples and details.

- The reader feels that $\mathrm{s} / \mathrm{he}$ is being invited to participate in the discussion of the topic and the construction of an argument through the author's use of directives phrases when presenting ideas.

- The idea (point of view) and the use of examples and details in the writing are unique, interesting, and engaging, indicating sophisticated thinking behind the writing.

- The reader feels that there is a central idea (point of view) in the text, but it is not fully developed.

- The writing shows some commitment to the topic with proper use of some supporting examples and details. But the examples are not always appropriate or effective.

- The reader occasionally feels that $s /$ he is being invited to participate in the discussion of the topic; but more often, the reader feels a lack of interaction with the writer.

- The idea (point of view) and the use of examples and details in the writing are safe and general, lacking uniqueness, sophistication, or thoughtfulness.

2

1 - The reader cannot find a consistent central idea (point of view) in the text.

- The writing does not show any commitment to the topic; rather, it is only an attempt (or a failed attempt) to answer a question. No examples or details are used to develop the topic.

- The reader feels that the writer is not concerned with the reader, and the writing is a confusing monologue instead of a clear dialogue between the writer and the reader.

- The writing is generic and lifeless. 


\begin{tabular}{ll}
\hline Affective & Voice Evoked by the Manner of Presentation \\
Dimension & \\
\hline
\end{tabular}

- The writer presents ideas and claims with language that shows authority and confidence.

- The reader feels that the writer has a clear stance on and a strong attitude toward the topic under discussion.

- The tone of the writing shows personality, adds life to the writing, and is engaging and appropriate for the intended reader.

- Word choice, and language use by extension, is varied, often interesting, sophisticated, and eye-catching to the reader.

- The writer presents ideas and claims very mildly, showing a lack of authority and confidence in what s/he is writing.

- The writer seems indifferent and does not have a clear stance on or attitude toward the topic under discussion.

- The writer writes in a monotone that does not engage the reader at all; oftentimes the reader find him- or herself drifting off while reading the text.

- Word choice or language use is flat, general, and dull, and thus unable to catch the reader's attention. 
353 | JOURNAL OF WRITING RESEARCH

\begin{tabular}{ll}
\hline Presence & Voice Evoked by Writer and Reader Presence \\
Dimension & \\
\hline
\end{tabular}

- The writer reveals him- or herself in the writing either directly or indirectly, giving the reader a clear sense of who the writer is as a unique individual.

- The reader feels that the writer is aware of and able to engage the reader effectively in a direct or subtle way.

- The sharing of personal backgrounds and experiences, if any, is effective, genuine, and engaging to the reader.

4

3

- The writer reveals him- or herself in the writing to some extent, leaving the reader with some sense of who s/he is.

- The reader feels that the writer is aware of and trying to engage the reader in a way, but with limited success.

- The sharing of personal backgrounds and experiences, if any, is genuine but not so engaging or effective to the reader.

2

1

- The reader has little or no sense of who the writer is as a unique individual instead of a generic, faceless person.

- The reader feels that the writer is not concerned with the reader or completely fails to engage the reader in any way.

- The sharing of personal backgrounds and experiences, if any, is generic, ineffective, and even inappropriate, making the reader feel annoyed. 


\section{Appendix B: The TOEFL Scoring Rubric}

\begin{tabular}{|c|c|}
\hline Score & Task Description \\
\hline 5 & $\begin{array}{l}\text { An essay at this level largely accomplishes all of the following: } \\
\text { - effectively addresses the topic and task } \\
\text { - is well organized and well developed, using clearly appropriate } \\
\text { explanations, exemplifications, and/or details } \\
\text { - displays unity, progression, and coherence }\end{array}$ \\
\hline 4 & $\begin{array}{l}\text { An essay at this level largely accomplishes all of the following: } \\
\text { - addresses the topic and task well, though some points may not be fully } \\
\text { elaborated } \\
\text { is generally well organized and well developed, using appropriate and } \\
\text { sufficient explanations, exemplifications, and/or details } \\
\text { displays unity, progression, and coherence, though it may contain } \\
\text { occasional redundancy, digression, or unclear connections } \\
\text { displays facility in the use of language, demonstrating syntactic variety } \\
\text { and range of vocabulary, though it will probably have occasional } \\
\text { noticeable minor errors in structure, word form, or use of idiomatic } \\
\text { language that do not interfere with meaning. }\end{array}$ \\
\hline 3 & $\begin{array}{l}\text { An essay at this level is marked by one or more of the following: } \\
\text { - addresses the topic and task using somewhat developed explanations, } \\
\text { exemplifications, and/or details } \\
\text { - displays unity, progression, and coherence, though connection of ideas } \\
\text { may be occasionally obscured } \\
\text { may demonstrate inconsistent facility in sentence formation and word } \\
\text { choice that may result in lack of clarity and occasionally obscure } \\
\text { meaning }\end{array}$ \\
\hline 2 & $\begin{array}{l}\text { An essay at this level may reveal one or more of the following weaknesses: } \\
\text { - limited development in response to the topic and task } \\
\text { - } \quad \text { inadequate organization or connection of ideas } \\
\text { - } \quad \text { inappropriate or insufficient exemplifications, explanations, or details to } \\
\text { - } \quad \text { support or illustrate generalizations in response to the task } \\
\text { - } \quad \text { an accumulation of errors in sentence structure and/or usage }\end{array}$ \\
\hline 1 & $\begin{array}{l}\text { An essay at this level is seriously flawed by one or more of the following } \\
\text { weaknesses: } \\
\text { - serious disorganization or underdevelopment } \\
\text { - little or no detail, or irrelevant specifics, or questionable responsiveness to } \\
\text { the task } \\
\text { - } \quad \text { serious and frequent errors in sentence structure or usage }\end{array}$ \\
\hline
\end{tabular}


Appendix C: Sample of an argumentative writing including voice dimensions

There are people who argue that too many girls go to university. They say that girls or women should get married at lower ages, stay at home and just take care of children and cook food. I absolutely disagree! 1 In my idea 2 every single person in this world should 3 have the right to decide for themselves, and education is one of those things. For nowadays almost everything depends on how educated you are. And also many things depend on education, for example the job you choose, and even the people you associate with, and etc 4 . I know girls who say "I didn't like to come to university, my family forced me to come to university."(5 Would you prefer to be living in a world full of educated people who can actually teach you something every day or a world full of people who don't even know how to act in different situations? 6 Education is a necessary thing for humans, just like clean water, food, electricity $\boldsymbol{\nabla}$, and so many other things that we need to survive. Learning feeds our minds, makes them grow and get better, and who says only men should grow and improve? 8 I think it's nothing but being a sexist. God said in Quran: "Women are equal to men." 9 Therefore, everything we consider for men, we have to consider for women too. This is not fair to say because most positions are taken by men, women should be kept aside and under the control of men. What if men were under the control of women? Let's turn the tables on arrogant men! 10

\begin{tabular}{|l|}
\hline Voice Indicators: \\
(1) Authority and \\
confidence \\
(Dimension 2) \\
(2) Self-identification \\
(Dimension 3) \\
(3) Strong attitude \\
(Dimension 2) \\
(4) Examples and details \\
(Dimension 1) \\
(5 Personal experiences \\
(Dimension 3) \\
(6 Reader engagement \\
(Dimension 3) \\
(7) Examples and details \\
(Dimension 1) \\
(8 Reader engagement \\
(Dimension 3) \\
( Examples and details \\
(Dimension 1) \\
(1) Reader engagement/ \\
Eye-catching word choice \\
(Dimensions 3/2) \\
\end{tabular}

